\title{
Estimation of ecosystem services value based on land use and cover change information derived from remote sensing data
}

\author{
Liyan Wang ${ }^{1,2}$, Chao Chen ${ }^{1 *}$, Kai Wang ${ }^{2 *}$ \\ ${ }^{1}$ College of Marine Science and Technology, Zhejiang Ocean University, Zhoushan, Zhejiang 316022, China \\ ${ }^{2}$ Chuzhou University, Chuzhou, Anhui 239000, China
}

\begin{abstract}
It is an effective method to study the value change of ecological services based on land use and cover change information. This paper analyzed the land use and cover change information in the research area, which is based on the remote sensing images and social statistics data of 2005, 2010, and 2015, and then, quantitative estimation of the ecosystem service value was performed. Yangtze-Huaihe river basin, China is a fragile ecological area, which is selected as the research area. During 2005-2015, the area of cultivated land and construction land was the main land use types in the study area, the land use and cover change in the study area were obvious, which was characterized by the increasing of construction land area and the decreasing of cultivated land area, and the total ecosystem services value in the research area has been decreasing continuously, the value from 34.376 billion yuan in 2005 to 26.161 billion yuan in 2015 .
\end{abstract}

\section{Introduction}

In recent years, the ecological and environmental problems which are owing to unreasonable development have become apparent increasingly. It does not only restricts the development of the local economy but also affects the evolution of the ecological environment in China $^{[1]}$. The natural environment conditions and utility that human beings depend on are formed and maintained through the ecosystem and ecological process, namely ecosystem services function ${ }^{[2]}$.

Many scholars are working on quantitative methods to calculate the value of ecosystem services and to evaluate them on a global scale ${ }^{[3]}$. For example, Costanza et $\mathrm{al}^{[4]}$ used the research results of predecessors to estimate the value of global ecological services. Xie Gaodi et $\mathrm{a}^{[5]}$ based on the evaluation model proposed by Costanza developed China's different terrestrial ecosystem per unit area ecosystem services value (ESV). This form is simple and reliable, so it has been widely used in China ${ }^{[6]}$. The impact of Land Use Change (LUC) on Ecosystem Services Value (ESV) has made some progress under the research of domestic and foreign scholars. For example, Song et.al [7] measured the influence of LUC on ESV through elasticity index. Blumstein et.al ${ }^{[8]}$, Lawler et.al ${ }^{[9]}$ studied the influence of LUC on ESV by analyzing the changes of LUC and ESV in the target area.

In this paper, based on the three-phase of remote sensing image data in the Yangtze-Huaihe river basin between 2005, 2010, 2015, the supervised classification method was used to obtain land-use and cover-change information. Then, the equivalent factor method was used to estimate the ecosystem services value of the study area. The study of this topic is of great significance for the sustainable development of the ecosystem.

\section{Methods}

\subsection{Calculation of the land-use dynamic index}

Land-use dynamic index $(K)$ is used to quantitatively analyze the change rate of land use in a certain period time in the region, to study the quantitative change characteristics of Land Use. The land-use dynamic index of different land-use types was calculated, and the dynamic land-use and cover-change in the Yangtze-Huaihe river basin were analyzed. The calculation expression of Land- use dynamic index is as follow:

$\mathrm{K}=\frac{U_{b}-U_{a}}{U_{a}} \times \frac{1}{T} \times 100 \%$

where, $\mathrm{K}$ is the dynamic index of a certain local class during the study period; $U_{a}$ is the area of the site at the beginning of the study, $\mathrm{U}_{\mathrm{b}}$ is the area at the end of the study. $\mathrm{T}$ is a period time. When $\mathrm{T}$ represents a year, $\mathrm{K}$ is the annual rate of change of a local class in the study area When $\mathrm{K}$ is equal to 0 , the shift in and out of the land-use type in the region keeps a balance, but the possibility of local changes in the land class cannot be ruled out.

\subsection{Equivalent factor method to estimate the ecosystem services value}

*Corresponding author's e-mail: chenchao@zjou.edu.cn, wangkai2003234@163.com 
Basing on the formula of ecosystem services value (ESV) of Costanza, etc. ${ }^{[5]}$ and the revised Chinese ecosystem services value equivalent factor tables of Xie Gaodi, etc. [4]. In combination with the reality of the Yangtze-Huaihe river basin (YHRB), modification of the economic value of the unit area of farmland natural food production every year (correction coefficient was 1.17 in Anhui province), ecosystem services value of construction land is zero. The value coefficients of the five land-use types in the study area were obtained by corresponding the different biomes of farmland-cultivated land, forest-woodland, grassland-grassland, waters-waters, wasteland-unused land.

Among the main crops in Anhui province, the proportion of cereals is larger, followed by beans, tubers and so on. According to the Statistical Yearbook of Anhui Province and basing on the average area, yield and average price of sown cereals, beans, and tubers in Anhui province from 2005 to 2015 , the average yield per unit area of grain in Anhui province was $5,494.33 \mathrm{~kg} / \mathrm{hm}^{2}$. Basing on the unit price of various crops in Anhui province in 2010, the average grain price is 1.7 yuan $/ \mathrm{kg}$. Finally, according to formula (2), the economic value of the natural grain yield in Anhui province is about 1334.34 yuan $/ \mathrm{hm}^{2}$.

$E_{n}=\frac{1}{7} \times \sum_{i=1}^{n} \frac{m_{i} q_{i} p_{i}}{M}$

where, $E_{n}$ is the economic value (yuan $/ \mathrm{hm}^{2}$ ) of cultivated land per unit area in the function of food production; $i$ is crop type; $P_{i}$ is the price of this crop (yuan $/ \mathrm{kg}$ ); $q_{i}$ is the yield per unit area of the crop $\left(\mathrm{kg} / \mathrm{hm}^{2}\right) ; m_{i}$ is the sown area $\left(\mathrm{hm}^{2}\right)$ of the crop; $M$ is the total sown area $\left(\mathrm{hm}^{2}\right)$ of each crop.

Thus, the ecosystem services value per unit area of each service function of each category in Anhui province is obtained, and the results are shown in Table 1 . Formula (3) and (4) are used to estimate the total ecosystem services value and each ecosystem services value in the study area separately.

$$
\mathrm{ESV}=\sum_{k=1}^{n}\left(V C_{k} \times A_{k}\right)
$$$$
\mathrm{ESV}_{f}=\sum_{k=1}^{n}\left(V C_{f k} \times A_{k}\right)
$$

where, ESV is the total ecosystem services value (yuan), $A_{k}$ is the area $\left(\mathrm{hm}^{2}\right)$ of the $K$ land-use type, $V C_{K}$ is the ESV coefficient of $K$ land use type (yuan $/ \mathrm{hm}^{2}$ year), $V C_{f K}$ is the coefficient of single service value, $\mathrm{ESV}_{\mathrm{f}}$ is the single ecosystem services value, $\mathrm{n}$ is the number of land-use types.

Tab.1 Basic per unit area ecosystem services value of each land-use type in the Yangtze-Huaihe river basin (Yuan/hm²)

\begin{tabular}{ccccccc}
\hline Ecosystem service functions & Woodland & Grassland & $\begin{array}{c}\text { Cultivated } \\
\text { land }\end{array}$ & Water area & $\begin{array}{c}\text { Construction } \\
\text { land }\end{array}$ & $\begin{array}{c}\text { Unused land } \\
\text { Gas condition }\end{array}$ \\
\hline Climate regulation & 3991.6100 & 912.3680 & 570.2300 & 0.0000 & 0.0000 & 0.0000 \\
Water conservation & 3649.2420 & 1026.4140 & 1015.0094 & 524.6116 & 0.0000 & 0.0000 \\
Soil formation and protection & 4447.7940 & 2223.8970 & 1665.0716 & 11.4046 & 0.0000 & 22.8092 \\
Waste disposal & 1494.0026 & 1494.0026 & 1870.3544 & 20733.5628 & 0.0000 & 11.4046 \\
Biodiversity conservation & 3717.8996 & 1243.1014 & 809.7266 & 2851.1500 & 0.0000 & 387.7564 \\
Food production & 114.0460 & 342.1380 & 1140.4600 & 342.1380 & 0.0000 & 11.4046 \\
Raw materials & 2965.1960 & 57.0230 & 114.0460 & 79.8322 & 0.0000 & 0.0000 \\
Entertainment culture & 1459.7888 & 45.6184 & 11.4046 & 6329.5530 & 0.0000 & 11.4046 \\
Total value & 24919.0510 & 8256.9304 & 7880.5786 & 54114.8270 & 0.0000 & 478.9932 \\
\hline
\end{tabular}

Anhui Province and consists of 14 cities and counties.

\section{Study area and data}

\subsection{Study area}

As shown in Figure 1, the Yangtze-Huaihe river basin in Anhui province, China stretches across the central part of
The total area is about $26800 \mathrm{~km}^{2}$, accounting for $19.1 \%$ of the total area of the province. This region has obvious advantages in geographical location, but due to its natural conditions, the ecological environment is fragile very much. 


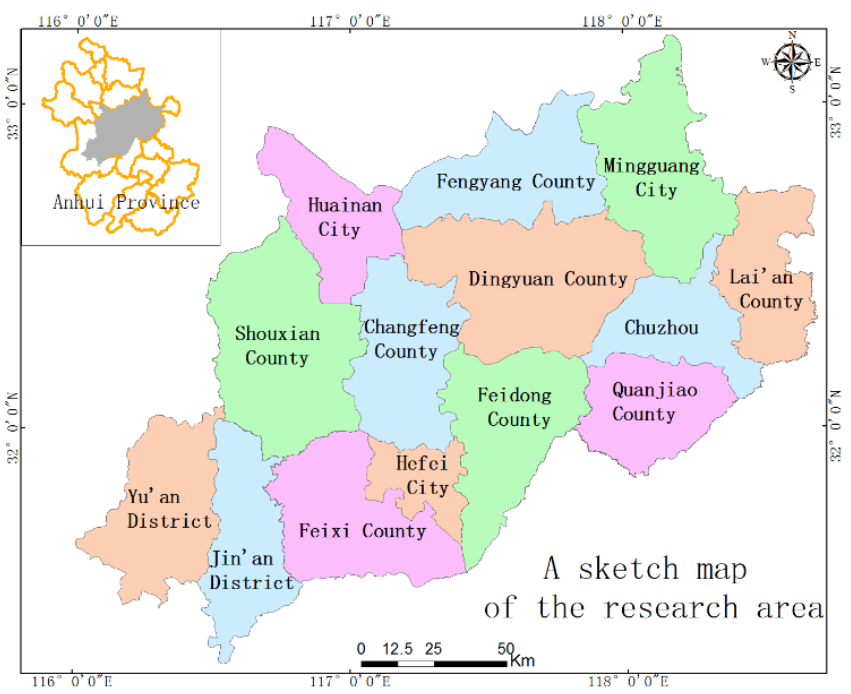

Figure 1. A sketch map of the research are

\subsection{Data}

The main data sources are land-use data and social statistics of the research area in 2005, 2010, and 2015. The social-economic statistical data during the study period were obtained from The Statistical Yearbook of Anhui Province (2005, 2010, 2015).

\section{Experimental results and analysis}

\subsection{Analysis of land-use and cover-change}

Based on the remote sensing image interpretation data of the Yangtze-Huaihe river basin in 2005, 2010, and 2015, the land-use types in the study area were divided into 6 categories: cultivated land, woodland, grassland, water area, construction land, and unused land using the supervised classification method (Figure 2). Besides, the spatial calculation function of ArcGIS 10.2 was used to calculate the area of each land-use type in each period of data, and the dynamic index of land-use was calculated by Excel. The results are shown in Table 2.

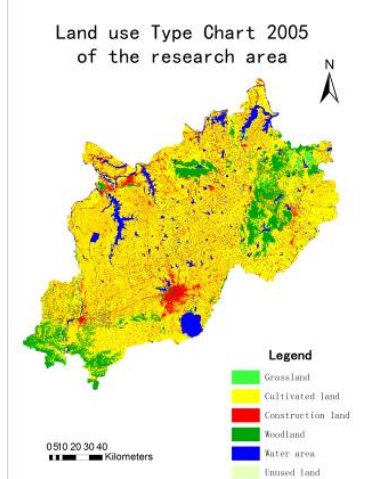

a. Land-use type chart 2005

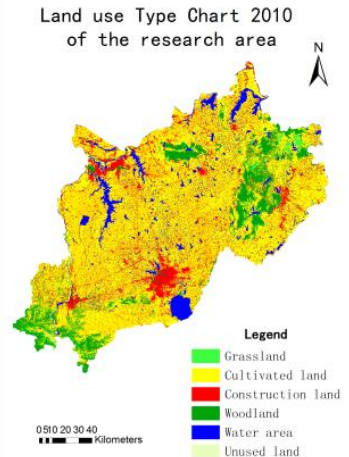

b. Land-use type chart 2010

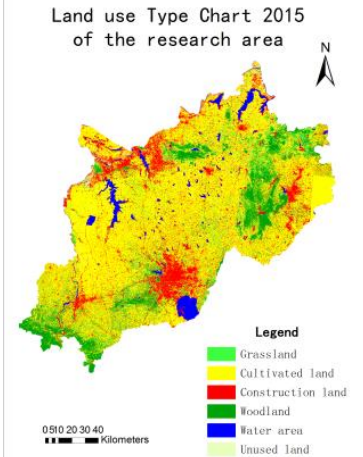

c. Land-use type chart 2015

Figure 2. Land-use types of the Yangtze-Huaihe river basin from 2005 to 2015

Tab.2 Area proportion of land-use types and dynamic index of the Yangtze-Huaihe river basin between 2005 and 2015 (\%)

\begin{tabular}{ccccccccc}
\hline Year & \multirow{2}{*}{ Project } & Grassland & Cultivated land & Construction land & Woodland & Water area & $\begin{array}{c}\text { Unused } \\
\text { land }\end{array}$ \\
\hline 2005 & \multirow{3}{*}{ Area } & 0.69 & 69.41 & 10.77 & 10.18 & 8.80 & 0.15 \\
2010 & & 0.62 & 66.05 & 13.95 & 10.18 & 9.00 & 0.21 \\
2015 & & 8.47 & 59.98 & 16.72 & 9.75 & 3.51 & 1.57 \\
$2005-2010$ & & -2.09 & -0.97 & 5.91 & 0.01 & 0.45 & 7.51 \\
$2010-2015$ & \multirow{2}{*}{ Dynamic index } & 254.70 & -1.84 & 3.97 & -0.85 & -12.20 & 132.65 \\
$2005-2015$ & & 113.02 & -1.36 & 5.53 & -0.42 & -6.01 & 94.96 \\
\hline
\end{tabular}

According to Table 2, from 2005 to 2015 , the land-use types in Yangtze-Huaihe river basin were mainly cultivated land and construction land, among which cultivated land accounted for the highest proportion, accounting for more than $65 \%$ of the total area at most. The proportion of unused land was the lowest, below 1.6 percent. From 2005 to 2015, the proportion of construction land in the total area increased by $5.95 \%$. It shows that the economy in the Yangtze-Huaihe river basin develops rapidly from 2005 to 2015, and the demand for construction land increases. From 2005 to 2010 , the overall variation of woodland and water area 
was not large, while from 2010 to 2015, the area of woodland and water area showed a trend of decrease. During the study period, the unused land area increased rapidly, and the land use dynamic index reached $94.96 \%$. This indicates that the surface vegetation tends to decrease, and the area of bare land such as land where the surface vegetation coverage is less than $5 \%$ has increased.

In a word, during the 10 years from 2005 to 2015, the construction land area in Yangtze-Huaihe river basin increased, the cultivated land area decreased. The economy got certain development, and various ecological projects began to be implemented gradually. The large increase of grassland has played a positive role in curbing the deterioration of the ecological environment and protecting the fragile ecosystem.

\subsection{Estimation in ecosystem services value}

According to Table 1 and the area of each land-use type, the value of ecosystem services in Yangtze-Huaihe river basin was calculated, and its change every five years was analyzed, as shown in Table 3 and Table 4.

Tab.3 Ecosystem services value of each land-use types in the Yangtze-Huaihe river basin from 2005 to 2015

\begin{tabular}{|c|c|c|c|c|c|c|}
\hline \multirow[b]{2}{*}{ Land Use } & \multicolumn{2}{|c|}{2005} & \multicolumn{2}{|c|}{2010} & \multicolumn{2}{|c|}{2015} \\
\hline & $\begin{array}{c}\text { Ecosystem service } \\
\text { value } / 10^{8} \text { yuan }\end{array}$ & $\begin{array}{c}\text { Percentage } \\
/ 100 \%\end{array}$ & $\begin{array}{c}\text { Ecosystem service } \\
\text { value } / / 10^{8} \text { yuan }\end{array}$ & $\begin{array}{c}\text { Percentage } \\
/ 100 \% \\
\end{array}$ & $\begin{array}{c}\text { Ecosystem service } \\
\text { value } / 10^{8} \text { yuan }\end{array}$ & $\begin{array}{c}\text { Percentage } \\
/ 100 \% \\
\end{array}$ \\
\hline Grassland & 1.52 & 0.44 & 1.36 & 0.40 & 18.74 & 7.16 \\
\hline $\begin{array}{l}\text { Cultivated } \\
\text { land }\end{array}$ & 146.61 & 42.65 & 139.50 & 41.10 & 126.69 & 48.43 \\
\hline Woodland & 67.97 & 19.77 & 67.99 & 20.03 & 65.10 & 24.88 \\
\hline Water area & 127.65 & 37.13 & 130.50 & 38.45 & 50.88 & 19.45 \\
\hline Unused land & 0.02 & 0.01 & 0.03 & 0.01 & 0.20 & 0.08 \\
\hline Total & 343.76 & 100 & 339.37 & 100 & 261.61 & 100 \\
\hline
\end{tabular}

Tab.4 Change in Ecosystem Services Value from 2005 to 2015 ( $10^{6}$ yuan)

\begin{tabular}{ccccccc}
\hline & Grassland & Cultivated land & Woodland & Water area & Unused land & Total \\
\hline $2005-2010$ & -15.90 & -710.84 & 1.81 & 285.14 & 0.72 & -439.07 \\
$2010-2015$ & 1737.58 & -1280.81 & -288.79 & -7962.00 & 17.49 & -7776.52 \\
$2005-2015$ & 1721.69 & -1991.65 & -286.98 & -7676.85 & 18.20 & -8215.59 \\
\hline
\end{tabular}

It can be concluded from Table 3 and 4 that the total ecosystem services value in Yangtze-Huaihe river basin decreased from 2005 to 2015 . The total value of ecosystem services in 2005, 2010, and 2015 was 34.376 billion yuan, 33.937 billion yuan, and 26.161 billion yuan respectively. From 2005 to 2010, the total ecosystem services value decreased by 439 million yuan. Among them, the change of ecosystem services value of cultivated land and water area is the most obvious. There was no significant change in the water area, and its ecosystem services value increased by 285 million yuan. The area of cultivated land showed a trend of decrease, and the value of its ecosystem services decreased by 710 million yuan. From 2010 to 2015, due to the increase of the grassland area, its ecosystem services value increased by 1.738 billion yuan, while the cultivated land area continued to decrease, and its ecosystem services value decreased by 1.281 billion yuan. The ecosystem services value of woodland was reduced by 289 million yuan. As the area of unused land increases, so does its ecosystem services value.

To sum up, from 2005 to 2015, the cultivated land area decreased, the construction land and grassland area increased, and the woodland and water area decreased slightly. However, according to the table of basic per unit area ecosystem services value, the ecosystem services value provided by woodland and water area is higher, while the construction land does not provide ecosystem services value. Therefore, the continuous decrease of the total ecosystem services value during the study period is in line with the actual situation of land-use change in the Yangtze-Huaihe river basin.

Tab.5 All types of ecosystem services value in the Yangtze-Huaihe river basin from 2005 to 2015

\begin{tabular}{|c|c|c|c|c|c|c|}
\hline \multirow{2}{*}{$\begin{array}{l}\text { Ecosystem service } \\
\text { functions }\end{array}$} & \multicolumn{2}{|c|}{2005} & \multicolumn{2}{|c|}{2010} & \multicolumn{2}{|c|}{2015} \\
\hline & $\mathrm{ESV} / 10^{8}$ yuan & percentage $/ \%$ & $\begin{array}{c}\mathrm{ESV} / 10^{8} \\
\text { yuan }\end{array}$ & percentage $/ \%$ & $\begin{array}{c}\mathrm{ESV} / 10^{8} \\
\text { yuan }\end{array}$ & percentage $/ \%$ \\
\hline Gas condition & 21.66 & 6.30 & 21.13 & 6.23 & 21.67 & 8.28 \\
\hline Climate regulation & 28.71 & 8.35 & 27.80 & 8.19 & 27.18 & 10.39 \\
\hline Water conservation & 77.68 & 22.60 & 78.27 & 23.06 & 44.47 & 17.00 \\
\hline $\begin{array}{l}\text { Soil formation and } \\
\text { protection }\end{array}$ & 43.55 & 12.67 & 42.01 & 12.38 & 43.46 & 16.61 \\
\hline Waste disposal & 88.05 & 25.61 & 87.43 & 25.76 & 56.86 & 21.73 \\
\hline Biodiversity conservation & 32.17 & 9.36 & 31.58 & 9.31 & 28.39 & 10.85 \\
\hline
\end{tabular}




\begin{tabular}{lcc} 
Food production & 22.40 & 6.52 \\
Raw materials & 10.41 & 3.03 \\
Entertainment culture & 19.13 & 5.57 \\
Total value & 343.76 & 100 \\
\hline & \\
From 2005 to 2015, among the values of various \\
service functions in Yangtze-Huaihe river basin, the value \\
of "Waste disposal" accounted for the highest proportion, \\
more than 20\%. The second is the value of "Water \\
conservation", which accounts for about 20\%. Among the \\
changes in the functional value of various ecosystem \\
services, the value of "Food production" decreases mainly \\
because of the decrease of cultivated land area. The \\
decline in the value of "Entertainment culture" is the \\
result of a trend towards the reduction of water area and \\
woodland area.
\end{tabular}

\section{Conclusion}

The development of the social economy and the land-use and cover-change information has a significant impact on the ecosystem services value. The distribution of precipitation in the Yangtze-Huaihe river basin, China is uneven within a year, and water shortage is prone to drought, so its ecosystem services value should be paid more attention to. Based on the remote sensing images and social statistical data from 2005 to 2015, the estimation of ecosystem services value is performed. The main conclusion is as follows: The total value of ecosystem services in the research area decreased from 34.376 billion yuan in 2005 to 26.161 billion yuan in 2015. Therefore, afforestation measures should be taken to protect the fragile ecosystems of the Yangtze-Huaihe river basin.

\section{Acknowledgment}

Thanks to the youth project of the cultivation project of excellent master's thesis of Zhejiang Ocean University, the national natural science foundation of China (41701447), and the special fund of basic scientific research operating expenses of research institutes of Zhejiang provincial universities (2019J00003).

\section{Reference}

1. Yao, Y., Ding, J.L., Wang, G., Zhang, F., Li, X., 2014. Response of ecosystem services value to land use change in Murghab-Tejen oasis, Turkmenistan. Arid Land Geography, 37(1): 134-143.

2. Chen, C., Fu, J. Q., Zhang, S., Zhao, X., 2019. Coastline information extraction based on the tasseled cap transformation of Landsat-8 OLI images. Estuarine, Coastal and Shelf Science. 217: 281-291.

3. Bagstad, K.J., Reed, J.M., Semmens, D.J., Sherrouse, B.C., Troy, A., 2016. Linking biophysical models and public preferences for ecosystem service assessments: A case study for the

\begin{tabular}{|c|c|c|c|}
\hline 21.38 & 6.30 & 19.74 & 7.54 \\
\hline 10.31 & 3.04 & 9.78 & 3.74 \\
\hline 19.46 & 5.73 & 10.06 & 3.84 \\
\hline 339.37 & 100 & 261.61 & 100 \\
\hline
\end{tabular}

4. Costanza, R., de Groot, R., Sutton, P., van der Ploeg, S., J.Anderson, S., Kubiszewski, I., Farber, S., Turner, R.K., 2014. Changes in the global value of ecosystem services. Global Environmental Change, 26: 152-158.

5. Zhang, W.H., Zhang, B., Xie, G.D.,2009. Support info of research on ecosystem services in China: Progress and perspectives. Journal of Natural Resources, 24(1): 1-10.

6. Xie, G.D., Lu, C.X., Leng, Y.F.,Zheng, D., Li, S.C., 2003. Ecological assets valuation of the Tibetan Plateau[J]. Journal of Natural Resources, 18(2): 189-196.

7. Song, W., Deng, X.Z., 2017. Land-use/land-cover change and ecosystem service provision in China. Science of the Total Environment, 576:705-719.

8. Blumstein, M., Thompson J.R., 2015. Land-use impacts on the quantity and configuration of ecosystem service provisioning in Massachusetts, USA. Journal of Applied Ecology, 52(4): 1009-1019.

9. Lawler, J.J., Lewis, D.J., Nelson, E., Plantinga, A.J., Polasky, S., Withey, J.C., Helmers, D.P., Martinuzzi, S., Pennington, D., Radeloff, V.C., 2014. Projected land-use change impacts on ecosystem services in the United States. Proceedings of the National Academy of Sciences of the United States of America, 111 (20): 7492- 7497. 